\title{
The combined strategy of mesenchymal stem cells and tissue-engineered scaffolds for spinal cord injury regeneration (Review)
}

\author{
ROSALIANA LIBRO, PLACIDO BRAMANTI and EMANUELA MAZZON \\ Department of Experimental Neurology, IRCCS Centro Neurolesi ‘Bonino-Pulejo’, I-98124 Messina, Italy
}

Received March 10, 2017; Accepted August 3, 2017

DOI: $10.3892 /$ etm.2017.4939

\begin{abstract}
Spinal cord injury (SCI) is a traumatic lesion that can result in the loss of motor or sensory neurons. Stem cell (SC)-based therapies have been demonstrated to promote neuronal regeneration following SCI, by releasing a range of trophic factors that support endogenous repair or by differentiating into neurons, or glial cells in order to replace the damaged cells. However, numerous limitations remain for therapies based on SC transplantion alone, including a low rate of survival/engraftment. Nevertheless, scaffolds are 3-dimentional substrates that have revealed to support cell survival, proliferation and differentiation in vivo, by mimicking a more favorable endogenous microenvironment. A multidisciplinary approach, which combines engineered scaffolds with SCs has been proposed as a promising strategy for encouraging spinal cord regeneration. The present review has focused on the regenerative potential of mesenchymal SCs isolated from different sources and combined with various scaffold types, in preclinical and clinical SCI studies.
\end{abstract}

\section{Contents}

1. Introduction

2. Engineered scaffolds

3. Stem cells in SCI

4. Combined approaches of MSCs and scaffolds

5. MSCs genetically modified and combined with scaffolds in SCI regeneration

6. Clinical studies with mesenchymal stem cells and scaffolds in SCI regeneration

7. Conclusions

Correspondence to: Dr Emanuela Mazzon, Department of Experimental Neurology, IRCCS Centro Neurolesi 'Bonino-Pulejo', Via Provinciale Palermo, Contrada Casazza, I-98124 Messina, Italy E-mail: emazzon.irccs@gmail.com

Key words: spinal cord injury, mesenchymal stem cells, scaffold, regeneration, tissue engineering

\section{Introduction}

Traumatic spinal cord injury (SCI) is a serious pathological condition characterized by a high mortality and disability rate, that affects approximately 250,000-500,000 people each year (1), implying a huge financial burden for health care.

Generally, SCI is the consequence of a physical trauma caused by compression, laceration or contusion of the spinal cord (2). This is called 'primary injury', and caused tissue impairment and the loss of neuronal cells that can not be recovered or regenerated, resulting in motor or sensory deficits $(3,4)$. The mechanical trauma triggers a strong inflammatory response (5). As consequence, the acute increase of pro-inflammatory cytokines, such as the tumor necrosis factor (TNF)- $\alpha$, interleukin (IL)-1 $\beta$, and IL- 6 promotes neuronal degeneration and the subsequent expansion of the lesion (6). The progressive destruction of the tissue surrounding the primary trauma is known as 'secondary injury', and different mechanisms are involved, such as edema formation, ischemia and hypoxia, excitotoxicity, oxidative stress, mitochondrial damage, invasion and activation of inflammatory cells that take part in the degeneration (6). In parallel, the loss of neural tissue and extracellular matrix (ECM) results in the formation of a large cystic cavity at the site of injury, infiltrated by inflammatory cells, such as reactive astrocytes, microglia, fibroblasts, and demyelinated axons that lead to the formation of the glial scar $(7,8)$, a physicochemical barrier that inhibits the endogenous axonal regeneration. Although, spinal cord possesses an intrinsic ability to regenerate $(9,10)$, the hostile microenvironment hinders it (11). The failure of axonal regeneration can be ascribed to the inhibitory molecules present in the injury site, such as the chondroitin sulfate proteoglycans (12), components of the glial scar, or myelin inhibitors (13), but it can also be limited by an insufficient trophic or mechanical support. Therefore, build a permissive environment, by attenuating the inflammatory response or by reducing the inhibitors of axonal growth, could be helpful to promote SCI repair.

In humans, the acute phase starts from two h after injury until two weeks, when begins the subacute phase, while chronic phase starts six months after SCI (14). The acute phase is generally considered the optimal therapeutic window for interventions. 
Despite the research advances, steroid drugs are the only treatment available for SCI, aimed to prevent the secondary damage. High-doses of methylprednisolone (MP) when administered within eight h of injury (by bolus $30 \mathrm{mg} / \mathrm{kg}$ over $15 \mathrm{~min}$, followed by $5.4 \mathrm{mg} / \mathrm{kg}$ of MP for $23 \mathrm{~h}$ ) are able to promote a notably neurologic recovery in patients affected by SCI (15).

On the other hand, cell-based therapies have obtained interesting results in SCI experimental models (16-18). Specifically, somatic cells, such as the olfactory-ensheathing cells, the Schwann cells and peripheral nerves have been transplanted in order to promote regeneration. Likewise, stem cells (SCs), including embryonic SCs, induced pluripotent SCs, mesenchymal SCs (MSCs), fibroblast-derived SCs, neural progenitor cells, have been used for the same goal. However, many issues still exist for using SCs in SCI regeneration, such as the low rate of cell survival/engraftment after transplantation, the appropriate route of administration or the optimal therapeutic window for cell engraftments.

Therefore, in order to overcome these issues, engineered scaffolds have been proposed as strategies for delivery SCs and improve regeneration after SCI $(19,20)$. Axonal regeneration in turn favor functional recovery, such as locomotor and sensorial improvements. In recent years, a variety of biomaterials have been employed in tissue engineering in order to support the regeneration of neural structures damaged after SCI.

\section{Engineered scaffolds}

Scaffolds provide a three-dimensional surrounding environment that confers a mechanical support to promote cell adhesion, migration and differentiation in vivo. In order to be applied in the regenerative medicine field, these devices must meet the following minimum criteria: biocompatibility, they must be immunologically inert; Biodegradability, they should degrade after a certain period of time in order to avoid a surgery to remove the implant; Mechanical strength, they must be resistant to mechanical stress in order to support growing tissues; Matrix properties, fiber and pore sizes may influence some cellular responses, including migration, proliferation and differentiation.

In the last years, different kind of scaffolds ranging from the basic hollow conduits to more complex architecture scaffolds have been designed in order to provide a mechanical support, to deliver cells, drugs or growth factors (21). Scaffolds can be classified on the basis of their composition in hydrogel and nanofibers. Hydrogel are three-dimensional macro-porous structures characterized by a high water content similar to soft tissues (22). They are difficult to sterilize and to handle because of their fragile nature. Hydrogel-based scaffolds can be delivered to the host as either preformed solid gel or viscous solution. In particular, injectable hydrogels have gained much attention in the field of SCI regeneration since they represent a minimally invasive technique (23). They can be coated with either natural or synthetic matrices that undergo to a rapid transformation from liquid to gel upon injection into the spinal cord (23). Hydrogel scaffolds have been used to fill the damaged area, but also as a carrier of SCs in order to create a favorable environment for tissue regeneration in SCI. These kinds of scaffolds have a lot of biomedical applications, such as drug delivery, regenerative medicine and more recently tissue engineering, thanks to their ability to encapsulate cells. Encapsulated cells are protected from the hostile environment in the injured spinal cord, and therefore they are more resistant and long-lived, but also less immunogenic (24), although the material mesh size can limit cell loading (25).

Nanofiber scaffolds are three-dimensional porous devices with a high surface area that once implanted not only promote cell adhesion, proliferation and differentiation because their architecture resemble the native ECM, but since their fibers can be orientated, they are also good network guidance channels that favor neurite outgrowth and cell alignment. The orientation of nanofibers within a scaffold, by directing cell growth, can significantly affects the regenerative process (26). Moreover, the nanofiber scaffolds can be either self-assembled or created by different manufacturing techniques, such as electrospinning (27). They can be used either alone or implemented with hydrogel (28). However, natural electrospun nanofibers have shared weak mechanical properties which limit their application as a nerve guide conduits (29).

Engineered scaffolds can be distinguished in films, membranes, foam, sponges, particles, fibers, and gels for their shape. They can be manufactured by using several fabrication techniques (i.e., freeze drying, particulate leaching, sponge replication, rapid prototyping, gas foaming, microsphere sintering and 3D printing) from a variety of biomaterials (30). Indeed, a first classification of engineered scaffolds can be done on the basis of source materials in natural, synthetic and composites.

Natural matrix-based scaffolds. Natural biopolymer-based scaffolds can be composed of natural polysaccharides, such as agarose and chitosan, or formed by biological components of the ECM such as collagen, fibrin and hyaluronic acid (HA). These biological matrices mimic the molecular microenvironment naturally found in neural tissues and they have also been used as vehicles to deliver cells and drugs.

The common advantages of natural scaffolds are: biocompatibility, biodegradability, low toxicity, intrinsic cellular interaction, plasticity, high porosity, permeability, hydrophilicity, while the disadvantages are: the expensive cost and the low mechanical stability. The main natural polymers used in spinal cord tissue engineering are agarose, alginate, chitosan, collagen, fibrin and gelatin and we have listed their main features in Table I.

In addition, acellular spinal cord (ASC) scaffolds are an alternative type of scaffolds for spinal cord tissue engineering. They are natural decellularated matrices obtained from chemical extraction (47), formed by the non-cellular part of the tissue: proteins, such as collagen, laminin, fibronectin and collagen. The extraction procedure consists in the removal of myelin and cells, leaving an intact ECM. The scaffolds are soft and flexible, containing linear guidance pores extending through their full length (47). However, the natural bio-polymers used to coated the scaffolds can be also artificial manufactured, as well as the acellular scaffold can be chemically extracted (48).

Synthetic matrix-based scaffolds. Synthetic polymer-based scaffolds are built from artificial materials, such as metals, 


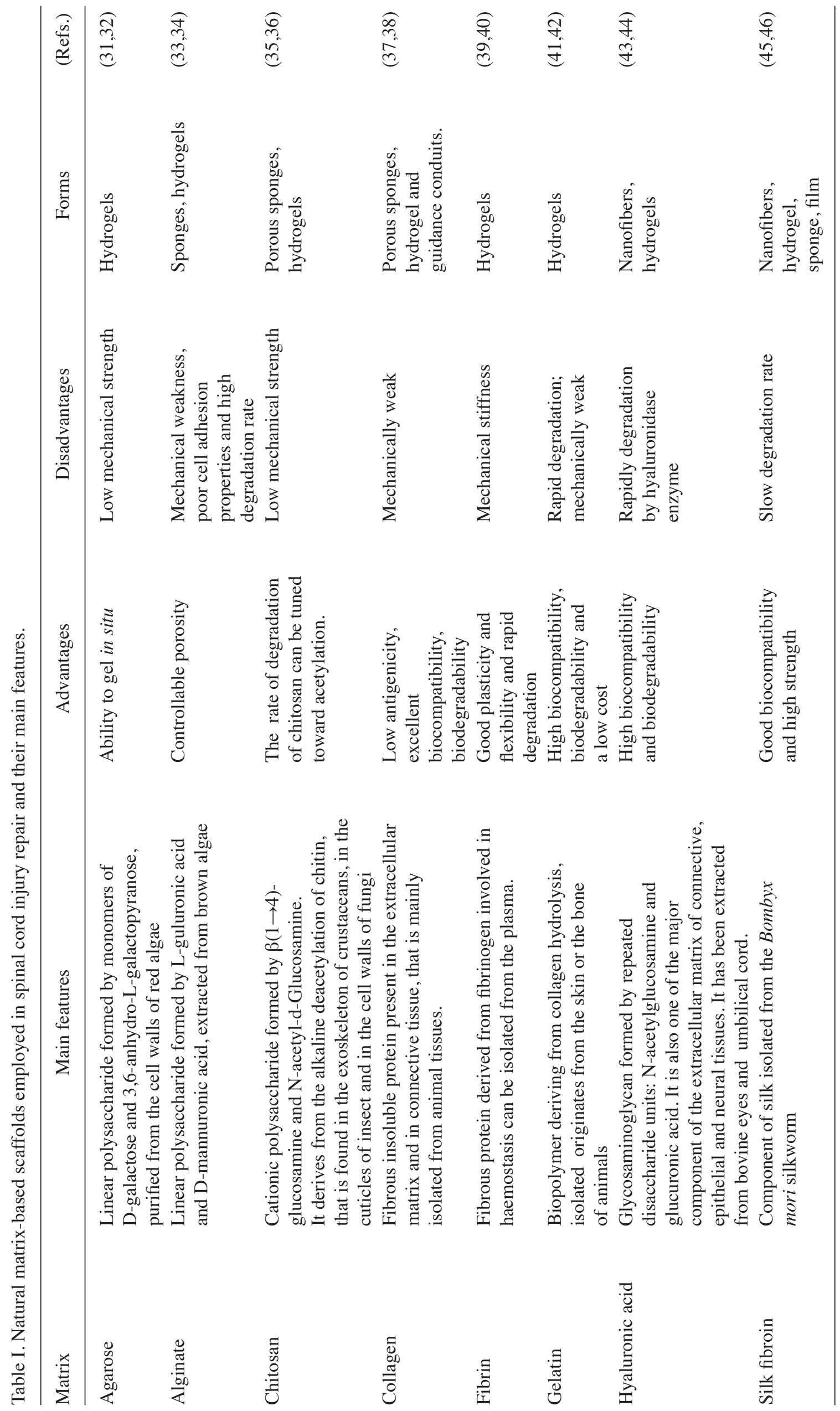


Table II. Synthetic matrix-based scaffolds employed in spinal cord injury repair and their main features.

\begin{tabular}{|c|c|c|c|c|c|}
\hline Matrix & Features & Advantages & Disadvantages & Forms & (Refs.) \\
\hline PLA & Aliphatic polyester & $\begin{array}{l}\text { Good porosity } \\
\text { and a good ratio } \\
\text { volume/area }\end{array}$ & $\begin{array}{l}\text { Low biocompatibility } \\
\text { and the discharge of } \\
\text { acidic degradation } \\
\text { products }\end{array}$ & $\begin{array}{l}\text { Sponge micro/ } \\
\text { nanoparticles; } \\
\text { hydrogels }\end{array}$ & $(49,50)$ \\
\hline PGA & Aliphatic polyester & $\begin{array}{l}\text { High crystallinity, } \\
\text { high strength, porosity }\end{array}$ & $\begin{array}{l}\text { Low solubility and } \\
\text { rapid degradation }\end{array}$ & Sponge & $(51,52)$ \\
\hline PLGA & $\begin{array}{l}\text { Aliphatic polyester, } \\
\text { derived from the } \\
\text { co-polymerization } \\
\text { of glycolic acid } \\
\text { and lactic acid. }\end{array}$ & $\begin{array}{l}\text { Good thermal stability, } \\
\text { fast degradation }\end{array}$ & $\begin{array}{l}\text { Less hydrophilic } \\
\text { than PGA; lower } \\
\text { strength }\end{array}$ & $\begin{array}{l}\text { Sponge, tubular, } \\
\text { Hydrogel and } \\
\text { film }\end{array}$ & $(53,54)$ \\
\hline PCL & Aliphatic polyester & $\begin{array}{l}\text { Easily degradation by } \\
\text { hydrolysis of its } \\
\text { ester bonds }\end{array}$ & Low degradation rate & Tubular, sponge & $(55,56)$ \\
\hline
\end{tabular}

PLA, poly(lactic acid); PGA, poly(glycolic acid); PLGA, poly(lactic-co-glycolic acid); PCL, poly(e-caprolactone).

ceramics, or polyester polymers. They can be classified in biodegradable, that degrade by hydrolysis, or non-biodegradable. Biodegradable scaffolds are the most used in the field of regenerative medicine and include: poly(glycolic acid) (PGA), poly(lactic acid) (PLA) and copolymers, polycaprolacton, polydioxanone, and polyurethanes, while non-biodegradable are polyvinyl alcohol, polyhydroxyethymethacrylate, and poly (N-isopropylacrylamide). Synthetic scaffolds shown some advantages compared to naturals: they can be produced on a large scale using reproducible and tunable method, can be fabricated with tailored architecture and properties (e.g., porosity, degradability and mechanical properties), according to their applications and are easy to sterilize. Conversely, the disadvantages are: the increased risk of rejection compared to natural scaffolds, they can produce acid degradation that lower the local $\mathrm{pH}$, leading to inflammation and cell-tissue necrosis. The most used synthetic and biodegradable scaffolds in the field of neural tissue engineering are PLA, PGA, poly(lactic-co-glycolic acid) (PLGA) and poly(e-caprolactone) (PCL) that have been summarized in Table II.

Composite matrices-based scaffolds. Composite scaffolds consist of a combination of different natural and synthetic polymers that have been designed in order to synergize the advantages of both and to overcome some of the disadvantages of the single-phase materials (57). For instance, gelatin, which shows poor mechanical strength is usually used in combination with other materials, such as hydroxyapatite, bioactive glass, HA and chitosan. Given that chitosan has also low mechanical strength, it has also been combined with other materials, natural or synthetic biomaterials (i.e., chitosan/collagen (58) or chitosan/poly(ethylene glycol) (59). Likewise, due the Alginate poor mechanical properties, it has been conjugated with agarose or chitosan (60).

Of note, composite scaffolds composed of natural and synthetic allow to overcome the issue of acidic products production by synthetic scaffolds alone, stabilizing the $\mathrm{pH}$. In addition, the combined approaches of two natural biopolymers can mimic better the ECM, which is a combination of several proteins, cytokines and growth factors. The advantages and disadvantages of natural, synthetic and composite scaffolds have been resumed in Table III.

Despite the therapeutic potential of scaffolds in tissue engineering, it has been found that biomaterials alone are not able to replace neuronal loss during SCI, as well as cell transplantation alone is not able to regenerate the spinal cord complex architecture and stability. Therefore, it has been proposed that transplantation of SCs seeded on various types of scaffolds can exert a synergistic effect on SCI recovery.

\section{Stem cells in SCI}

The basic principles of tissue engineering involving the combination of SCs with a natural or a synthetic matrix (scaffold). In order to be used on a large scale and to be transplanted SCs must have the following characteristics: accessibility, their removal should not require invasive procedures; availability, SCs must be available in sufficient numbers to allow the transplant; plasticity, they must differentiate into different cell lines; mitotic stability, should maintain a stable karyotype after several cell divisions; low risk, their use must not induce immunological and neoplastic reactions; ethics acceptability, their use must not cause ethical problems.

In the context of SCI, cultured Schwann cells and neural progenitor cells could be the optimal candidates for nerve regeneration, because Schwann cells are known to release growth factors that enhance axonal regeneration and to promote re-myelination (65), while neural progenitor cells can be easily induced to differentiate in neurons or glial cells (66). However, these cells have not yet been used in the clinic because of technical and ethical problems. Indeed, harvesting these cell lines is limited by donor morbidity and by their 
Table III. Advantages and disadvantages of natural, synthetic and composite scaffolds.

\begin{tabular}{lll}
\hline Type of scaffold & \multicolumn{1}{c}{ Advantages } & \multicolumn{1}{c}{ Disadvantages } \\
\hline NATURAL & High biocompatibility, fast degradation & $\begin{array}{l}\text { Low mechanical features, } \\
\text { immunogenic and infection risks } \\
\text { SYNTHETIC }\end{array}$ \\
COMPOSITE & $\begin{array}{l}\text { Good mechanical properties, } \\
\text { thermal stability } \\
\text { Enhanced functionality: biocompatibility } \\
\text { and conductivity.Allow to overcome the } \\
\text { the problems of using single materials }\end{array}$ & $\begin{array}{l}\text { acid production } \\
\text { Sophisticated manufacturing techniques } \\
\text { to combine different materials together, } \\
\text { expensive }\end{array}$ \\
\hline
\end{tabular}

limited expansion capacity. These limitations have encouraged the efforts to look for alternative cell sources. Among sources of SCs, MSCs have been extensively investigated, because they show advantages compared to other SCs. First, MSCs are adult SCs, thus they allow to avoid the ethical issues regarding the use of embryonic SCs. Secondly, MSCs can be easily isolated compared to other sources of SCs. Third, MSCs have shown a great capacity of regeneration and immune-modulatory properties (67). The major advantage of MSCs compared to other SCs is that they can be autologously sourced. Autologous cells are devoid of the risk of immune rejection.

MSCs are multipotent cells able to differentiate into different mesenchymal tissues. According to the International Society for Cellular the minimal criteria for classify SCs as MSCs are: fibroblast-like morphology and plastic-adherence under standard culture conditions; positive expression for the surface markers CD73, CD90 and CD105; negative expression for CD45, CD34, CD14 or CD11b, CD79a or CD19 and for the major histocompatibility complex class II surface molecules; ability to differentiate into osteoblasts, adipocytes and chondroblasts in vitro (68). They can be isolated from various sources such as the bone marrow (69), umbilical cord (70), placenta (71), fat (72), amniotic fluid (73), endometrium and oral cavity (74).

MSCs create a microenvironment favorable for neuronal regeneration by counteracting many harmful events, such as inflammation and apoptosis (75). In addition, MSCs are potentially able and to promote axonal regeneration through two main distinct mechanisms: i) a paracrine effect, by releasing a wide range of trophic factors, such as brain-derived neurotrophic factor (BDNF), nerve growth factor (NGF), vascular endothelial growth factor (VEGF), fibroblast growth factor (FGF)-2, transforming growth factor (TGF)- $\beta$ and insulin-like growth factor (IGF)-1 (76) or ii) by differentiating or by promoting trans differentiation into neurons or glial cells (77). Although MSCs have been shown to exert a variety of beneficial effects in several CNS disease models, including SCI $(78,79)$, the inflammatory environment during the acute phase of SCI can lead to low rates of MSCs engraftment and survival (80).

Indeed, different limitations still exist for using MSCs as a therapeutic tool for SCI. One of the most important issues is the selection of the best cell transplantation routes. A disadvantage of MSCs infusion could be cell trapping in other organs, as well as the risk of immune reactions, the low neural differentiation rate, and low survival rate.
Given the potential of MSCs in SCI, many researchers have searched novel strategies to promote MSCs engrafts. In this regard, combining MSCs with scaffolds could be a promising strategy to promote MSCs survival, proliferation and differentiation.

\section{Combined approaches of MSCs and scaffolds}

Bone marrow-derived mesenchymal stem cells (BMSCs) and scaffolds in SCI regeneration. Itosaka and colleagues (81) have reported that BMSCs seeded on fibrin scaffold and injected into hemisected rat spinal cord showed an increased survival, as well as an enhanced ability to migrate into the damaged spinal cord, to differentiate in neurons, compared with the BMSCs implanted alone. In addition, they observed a significant improvement of locomotor function at 14, 21 and 28 days after transplantation, according to the Basso-Beattie-Bresnahan (BBB) Loco-motor Rating Scale (82).

Instead, Kim et al (83) compared the efficacy of allogeneic BMSCs conjugated with PLG scaffolds or chitosan scaffolds, with intralesional injected MSCs in the contusive SCI rat model. For six weeks after SCI, the authors observed a higher success rate of BMSCs engraftment and a major functional recovery, according to the BBB scale in both scaffold groups compared with MSCs infused alone. These improvements observed in the scaffold groups were ascribed to the increased release of neurotrophic factors, such as BDNF and NGF, in the site of injury, known to promote cell survival and spinal cord regeneration.

In line with these findings, another study has reported that BMSCs seeded on a 3D collagen scaffold and implanted in the hemisected rat spinal cord, after eight weeks attenuated the expression of inflammatory cytokines (TNF- $\alpha$, IL-1 $\beta$, and IL-6) in the injured microenvironment and conferred neuroprotection by increasing the expression of neurotrophic factors, such as the glial cell line-derived neurotrophic factor (GDNF), the hepatocyte growth factor (HGF), and the VEGF (84) compared to BMSCs or scaffold transplanted alone. In another study (85), BMSCs were seeded on a gelatin sponge cylindrical scaffold previously covered with a PLGA film, in order to prevent gelatin deformation. Eight-week after implantation, it was found that the cell- composite scaffold was able to reduce inflammation, by decreasing the cytokine levels (TNF- $\alpha$ and IL-1 $\beta$ ), as well as the number of CD68+ cells (active macrophage and microglia) and to promote 
angiogenesis, by increasing the expression of VEGF and hypoxia-inducible factor- $1 \alpha$ (HIF-1 $\alpha$ ) into the transected SCI rat model. Moreover, it was also observed a reduced cavity area in the cell-scaffold group compared with the scaffold group alone (85). On the other hand, eight weeks after transplantation BMSCs seeded on ASC scaffold were able to bridge the lesion cavity and to attenuate inflammation, as demonstrated by reducing infiltration of macrophages and lymphocytes, in the site of injury of transplanted acute SCI hemisected rat model (86). Moreover, it was observed a decreased apoptotic neuronal rate and a concomitant locomotor recovery in the cell-scaffold group compared with the scaffold group alone. Likewise, Chen et al (87), by adopting the same cell-scaffold constructs in the hemisected SCI rat model, observed similar improvements in motor function just eight weeks after implantation compared with the group transplanted with only scaffold. In this case, the beneficial effects of the cell-scaffold constructs were mainly ascribed to the inhibition of apoptosis, as proven by the lower caspase-3 levels, which result in decreased oligodendrocytes and axonal loss. Li and colleagues (88) have proposed an alternative approach which combines two different biomaterials on a unique scaffold, in order to minimize the disadvantages of the single material, not only to seed cells but also to deliver neurotrophic factors. In brief, fibroin/gelatin coated sponge scaffolds (NF-GS) were engineered in order to contain neurotrophin-3 (NT-3), which is known to be involved in neurogenesis by promoting the differentiation of new neurons (89). These NF-GS/NT3 scaffolds have been implanted at the injury site of both transected rat and canine hemisected models to bridge the gap. A decreased number of CD68 positive cells (immune reactive cells) and TNF- $\alpha$ levels have been observed, after seven days of transplantation, compared with scaffolds containing fibroin only. Four weeks after transplantation, it was observed an increased number of NF (neurofilament) positive cells in the rostral and caudal areas near the injury/graft site of the spinal cord, which may indicate the regrowth of the nerve fibers (88). In this regard, Raynald et al (90) have found that BMSCS seeded on HA-scaffold modified by poly-L-lysine (HA-PLL) transplanted in the hemitransected rat spinal cord possess an increased ability to differentiate in both neurons and astrocytes, as demonstrated by positive cells for the neuronal nuclear antigen $(\mathrm{NeuN})$ or for the glial fibrillary acidic protein (GFAP), compared with BMSCs transplanted alone or with the experimental group which received only scaffolds without cells. Moreover, these scaffolds increased MSCs survival (over eight weeks in immune competent rats) and promoted hind-limb locomotor recovery in SCI. Zaminy et al (91) have successfully induced the differentiation of allogenic BMSCs in Schwann cells in vitro, before transplantation, as demonstrated by the expression of glial genes, such as p75, S100, NGF, BDNF, NT-3 and the peripheral myelin protein 22 (PMP22). These transdifferentiated cells were then engrafted via collagen scaffold in the hemisected rat spinal cord. Interestingly, it was observed a moderate improvement of hind limb motor function and a prominent sensorial recovery in the BMSCs + scaffold group compared with rat implanted with the scaffold alone. These improvements have been ascribed to the ability of the induced-Schwann cells to release a wide range of neurotrophic factors, such as NGF, BDNF, CTNF, and GDNF and VEGF, such as VEGF and HGF that promote myelin sheath formation and neovascularization in vivo (91). Although BMSCs are the most investigated MSCs in the field of regenerative medicine, probably due their pioneeristic discovery (92), new attractive sources of MSCs have been explored in the last decade. All the studies reported in this paragraph have been summarized in Table IV.

Endometrial MSCs and scaffolds in SCI regeneration. MSCs derived from the endometrial SCs (EnSCs) seeded on PLGA electrospun nanofibrous scaffold have demonstrated to possess an increased differentiation trend into motor-neuron like cells, compared with EnSCs cultured under standardized conditions (93). Similarly, human EnSCs (hEnSCs) loaded on poly $\varepsilon$-caprolactone (PCL) nanofibrous scaffold were more prone to differentiate into motor-neuron like cells in vitro compared with hBMSCs seeded on the same scaffolds and with control groups (grown on tissue culture polystyrene), as demonstrated by increased levels of neural markers, such as $\beta$-tubulin III, islet-1, neurofilament-H, HB9, Pax6, and choactase-positive motor neurons (94). Ebrahimi-Barough et al (95) cultured the hEnSCs in vitro with Ly294002, an inhibitor of phosphatidylinositol 3-kinase (PI3K)/Akt signal pathway, and then seeded these cells on a composite scaffold constituted by PCL/collagen electrospun fibrous. It was observed that hEnSCs loaded on this kind of scaffold differentiated more in motor neuron-like cells compared with hEnSCs expanded onto classic tissue culture plates. The in vitro studies of EnSCs and scaffolds have been reported in Table V.

However, only one study in vivo has demonstrated a regenerative potential of EnSCs in SCI. Specifically, EnSCs seeded on electrospun PCL scaffolds and transplanted into the hemisected SCI rat have shown to prevent the cavity formation, contributing to the functional recovery after SCI (96) (Table VI).

Adipose (AD)-derived MSCs and scaffolds in SCI regeneration. MSCs derived from ADSCs were stimulated to differentiate into Schwann cells in vitro. Differentiated cells were then loaded into collagen scaffolds and transplanted in hemisected SCI rat model (97). SCI rats transplanted with Schwann cell derived from ADSCs + scaffold showed an improved sensory-motor recovery compared with SCI rats which received Schwann cell differentiated from BMSCs and also compared with rats implanted with the scaffold without cells. These findings indicated that scaffolds alone are less efficacious than scaffold + cells and ADSCs could be a promising source of exogenous Schwann cells for SCI regeneration. On the other hand, different kinds of biomaterials have been tested in vitro in order to design the best scaffold-device for cell deliver. In this regard, Gao et al (98) demonstrated the ability of ADMSCs to differentiate into neuron-like cells in vitro and their increased survival on porous scaffolds derived from photocurable chitosan and gelatin. Conversely, Wenchen et al (99) have demonstrated a good biocompatibility of ADSCs on silk fibroin-chitosan scaffold. These two studies in vitro suggested two different approaches for using ADSCs and scaffolds in regenerative medicine (Table VI). However, new preclinical studies are needed to validate the combination of ADSCs with different matrix-based scaffolds as suitable tools for tissue engineering. 


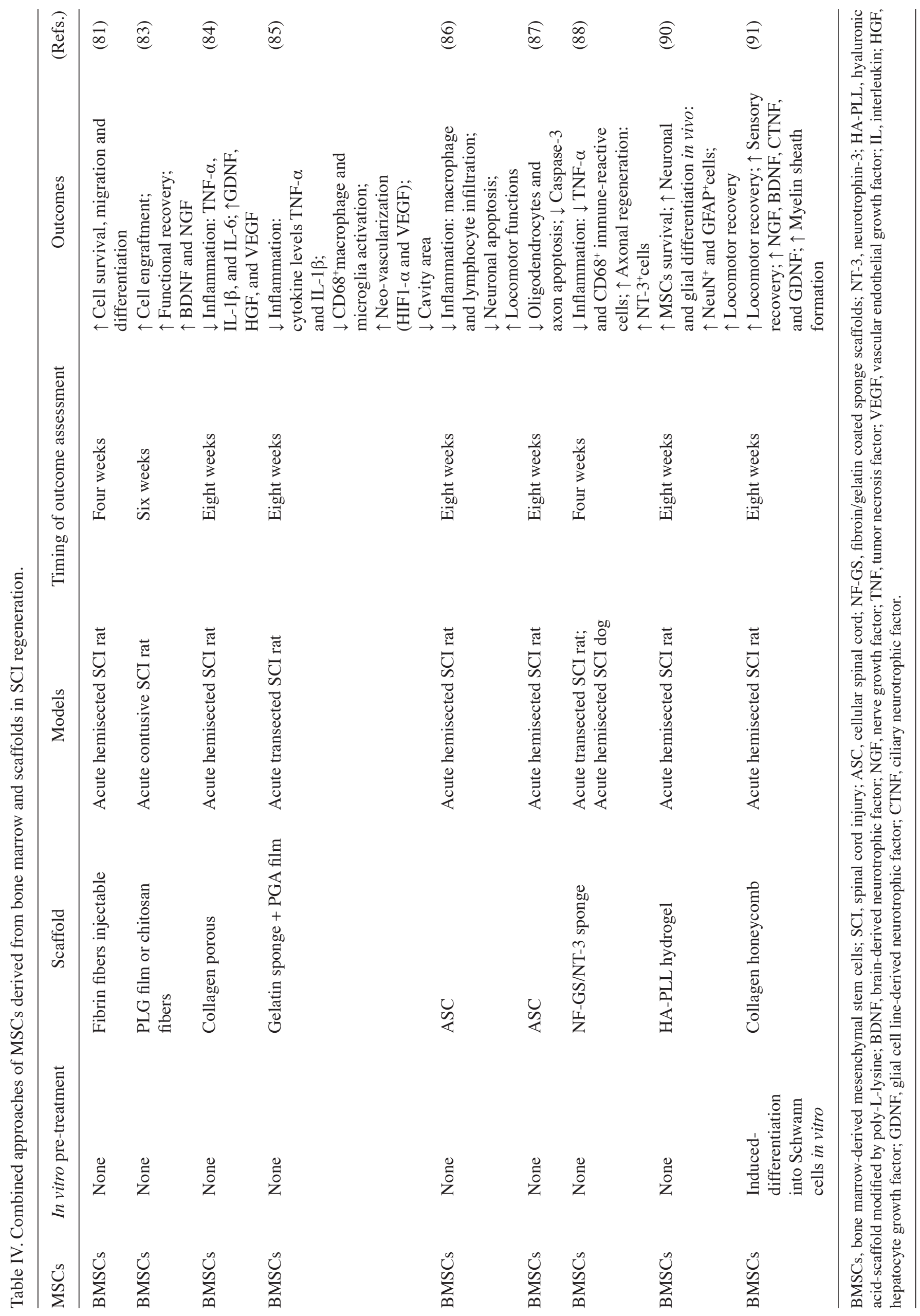


Table V. In vitro studies of scaffolds and MSCs derived endometrium.

\begin{tabular}{|c|c|c|c|c|}
\hline MSCs & In vitro & Scaffold & Outcomes & (Refs.) \\
\hline hEnSCs & $\begin{array}{l}\text { Induced-differentiation } \\
\text { into motor-neuron like cells }\end{array}$ & PLGA Nanofibrous & $\uparrow$ Differentiation in vitro & (93) \\
\hline $\begin{array}{l}\text { hEnSCs } \\
\text { vs. hBMSCs }\end{array}$ & $\begin{array}{l}\text { Induced-differentiation } \\
\text { into motor-neuron like cells }\end{array}$ & & & (94) \\
\hline hEnSCs & $\begin{array}{l}\text { Induction of neuronal differentiation } \\
\text { through neurogenic medium } \\
\text { containing a PI3K/Akt inhibitor }\end{array}$ & & & (95) \\
\hline
\end{tabular}

hEnSCs, human endometrial stem cells; hBMSCs, human bone marrow-derived mesenchymal stem cells.

Fetal MSCs and scaffolds in SCI regeneration. Caron et al (100) combined a lyophilized hydrogel scaffold with the arginine-glycine-aspartic acid (HG-RGD) tripeptide, which improves cell adhesion, to enhance cell/biomaterial interactions (101). Then, human umbilical cord blood-MSCs (hUCB-MSCs) were let to grow for 14 days on these sponge-like HG-RGD scaffolds in order to deposit ECM. By cellular tracking, it was found that MSCs seeded on this kind of scaffold survived for a longer time (more than 21 days) in vivo compared with other studies which employed other scaffold supports (approximately 14 days) (102). In addition, MSCs loaded with HG-RGD scaffold were delivered into the site of injury of the rat compression model of SCI, where they were able to modulate the inflammatory responses, by increasing the rate of M2 macrophages in vivo, compared to cells or scaffold transplanted alone (100). Similarly, hUCB-MSCs seeded on ASC scaffold were implanted in the hemisected rat SCI model (103). Eight-weeks post-implantation, it was observed a more prominent locomotor recovery in the cell + scaffold group compared with the group implanted with the scaffold alone. On the other hand, Jiao and colleagues (104) compared the regenerative potential ofhUC-MSCs loaded on a specific composite scaffold composed of silk fibroin/alginate and coated with GDNF (SF/AGs/GDNF scaffold) with the SF/AGs/GDNF scaffold group alone in a compressive SCI rat model. Eight weeks after implantation, they found that combining the composite scaffold with hUC-MSCs improved the locomotor recovery after SCI. The best therapeutic effect exerted by this combined approach has been ascribed to the lower rate of neuronal necrotic cells and reduced cytokine levels, including IL-1 $\beta$, IL-6 and TNF- $\alpha$, in rat spinal cord. Moreover, it was found an enhanced percentage of positive cells for the neuronal markers MAP2, NeuN and Nestin, indicating an increased trend of hUC-MSCs seeded on this kind of scaffold to transdifferentiate in neurons. Li et al (105) transplanted collagen-based scaffold, derived from bovine aponeurosis (106), known as Neuroregen ${ }^{\mathrm{TM}}$, in combination with hUC-MSCs in chronic SCI transection model. One year after transplantation, it was observed a locomotor recovery that was ascribed to neural regeneration and to the reduction of glial scar formation.

Conversely, Wang et al (107) evaluated the effect of MSCs isolated from amniotic membrane loaded [amniotic fluid MSCs (AF-MSCs)] on a fibroin-silk scaffold and transplanted in chronic hemisected rat spinal cord, one week after SCI induction. Four weeks after implantation, it was observed a hind limb functional recovery in the cell-scaffold device implanted group compared with the groups which received the blank scaffold or cells alone. Similarly, amniotic epithelial cells (AECs) isolated from the rat amnios were seeded on acellular muscle scaffolds obtained through chemical extraction in hemisected SCI rat. Four weeks after implantation, it was observed an increased functional recovery in the hind limb, according to the BBB scale, compared with the scaffold group alone. Moreover, it was reported an increased percentage of $\mathrm{NF}^{+}$cells, which indicated an increased regeneration (108), Table VI.

Dental MSCs and scaffolds in SCI regeneration. MSCs derived from oral cavity could be a promising SC source to be employed in the scenario of SCI $(109,110)$. Indeed, several reports have highlighted that MSCs derived from oral tissues, including the dental pulp SCs (DPSCs), have a natural predisposition in differentiating towards neuronal-like cells $(111,112)$, compared with other MSCs sources, probably owing to their origin from neural crest (113).

In this regard, Zhang et al (114) seeded DPSCs on chitosan scaffolds and induced cells to differentiate toward neuronal phenotype by culturing them in a specific neurogenic medium for 14 days. Notable, it was observed that chitosan scaffold enhanced the differentiation rate of DPSCs, increasing the number of positive cells for the oligodendrocyte marker CNPase, for the astrocyte marker GFAP and the neuronal markers MAP-2. Following neural differentiation, these cells were transplanted into a chronic contusive SCI rat model (one week after SCI). Increased levels of neurotrophic factors, such as BDNF, GDNF, b-NGF, and NT-3 were found in the DPSC/chitosan-scaffold group compared with the group which received only DPSCs without scaffold (control group) (Table VI). This enriched environment created by the cell-scaffold implant may be responsible for the hind limb locomotor recovery observed in these animals.

\section{MSCs genetically modified and combined with scaffolds in $\mathrm{SCI}$ regeneration}

One potential strategy to promote axonal regeneration after SCI consists in creating a microenvironment enriched of 


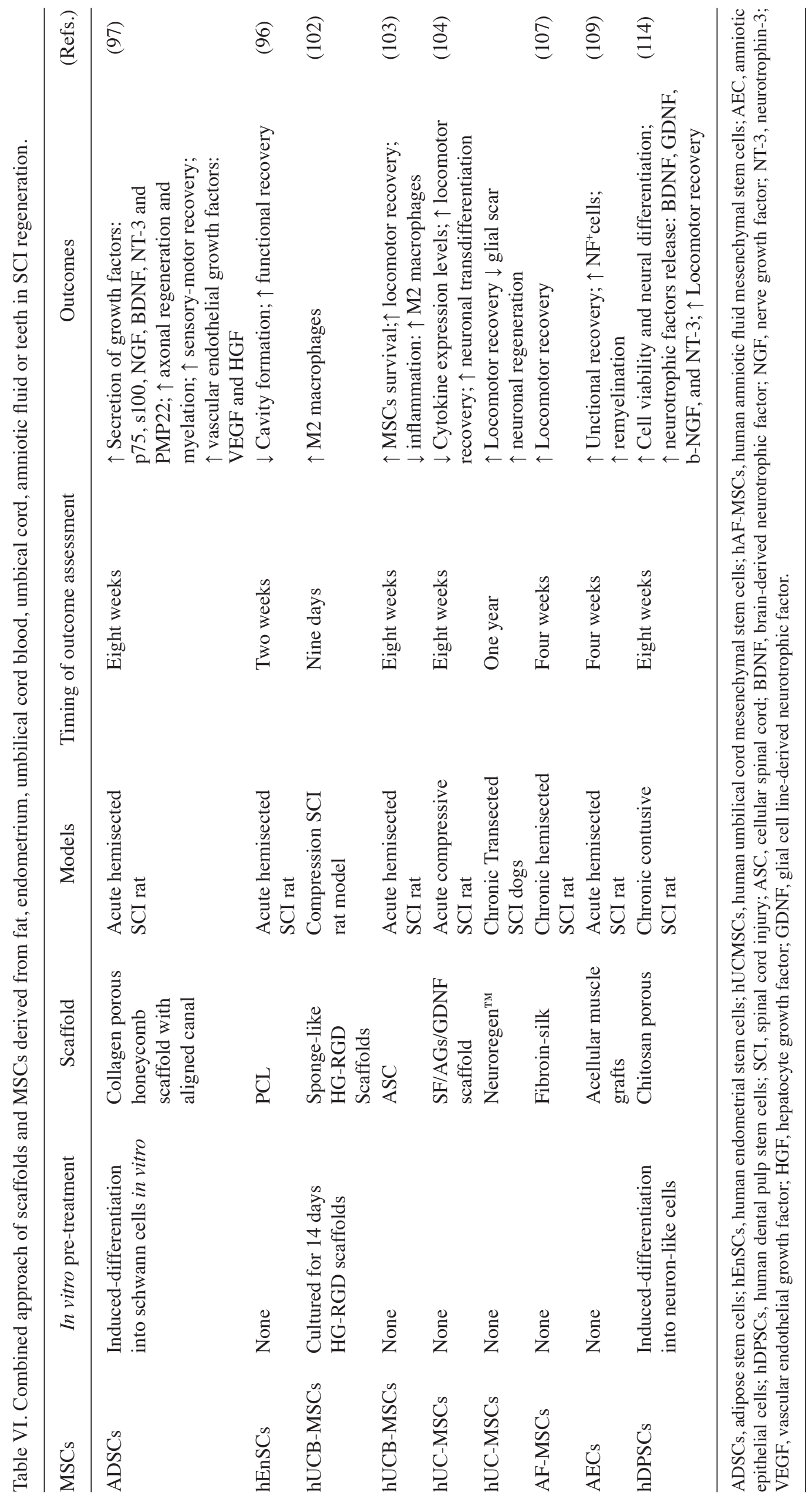


neurotrophic factors which favor MSCs survival and differentiation. MSCs can be genetically manipulated to overexpress neurotrophic factors, such as BDNF, NT-3 and the neurotrophin-3 receptor (TrkC) and GDNF (115) or alternatively the expression of deleterious proteins can be suppressed by gene silencing.

BMSCs overexpressing BDNF were encapsulated in alginate-based anisotropic capillary hydrogels and grafted into the lesion of hemisected rat spinal cord (116). Interestingly, these alginate scaffolds conjugated with BMSCs overexpressing BDNF showed an enhanced ability to induce axonal regeneration four weeks after implantation, as proved by the reduced cavity formation, compared to the control group which received scaffold plus BMSCs expressing only the Green Fluorescent Protein (GFP) (116).

Rat BMSCs engineered to over-secrete NT-3 and TrkC were co-cultured in vitro with Schwann cells in a gelatin sponge scaffold. After growing in culture for 14 days, BMSCs were able to differentiate into neuron-like cells, expressing neuronal markers and showing typical neuronal electrical activity. Then, differentiated cells loaded on the scaffold were implanted into the rat SCI transection models (117). Eight weeks after implantation it was observed a recovery of hind limb locomotor function in the cell-scaffold group compared with the group that received cells alone without the scaffold device.

Wang et al (118) silenced the expression of Nogo-66 receptor gene in BMSCs and Schwann cells, a gene that is likely to be involved in nerve growth inhibition (119), before seeding them on a PLGA scaffold and to co-transplant cells in the hemisected SCI rat model. Four weeks after transplantation, it was observed a decreased cavity formation, which was consistent with the improvement of the lower extremity motor function observed compared with the control group (transplanted with the cell-scaffold construct expressing wt Nogo-66). On the other hand, MSCs overexpressing TrkC were placed on a gelatin sponge scaffold and transplanted in vivo in the transected SCI rat model. After that, vectors carrying human NT-3 gene were injected into the site of injury. Of interest, it was observed an increased migration of MSCs overexpressing TrkC into the site of injury which contained high NT-3 levels, compared to the control group (BMSCs no genetically modified) (120). All the studies described in this paragraph are listed in Table VII.

\section{Clinical studies with mesenchymal stem cells and scaffolds in SCI regeneration}

Clinically, SCI is a heterogeneous pathological condition. Patients suffering from SCI show different tracts of injured spinal cord, various degrees of disability and stages of disease. By searching for clinical trials which combine the use of scaffold with MSCs, we have found only two published studies in 'PubMed' that meet our criteria.

In 2016, a pioneer clinical trial study (121) has enrolled five patients ( 4 male and 1 female) affected by complete SCI at the cervical or thoracic level (C5-T12), according to the criteria of the American Spinal Injury Association (ASIA) Impairment Scale, suffering from 2 to 32 months, with an age average comprised from 27 to 56 years. In this study, the NeuroRegen

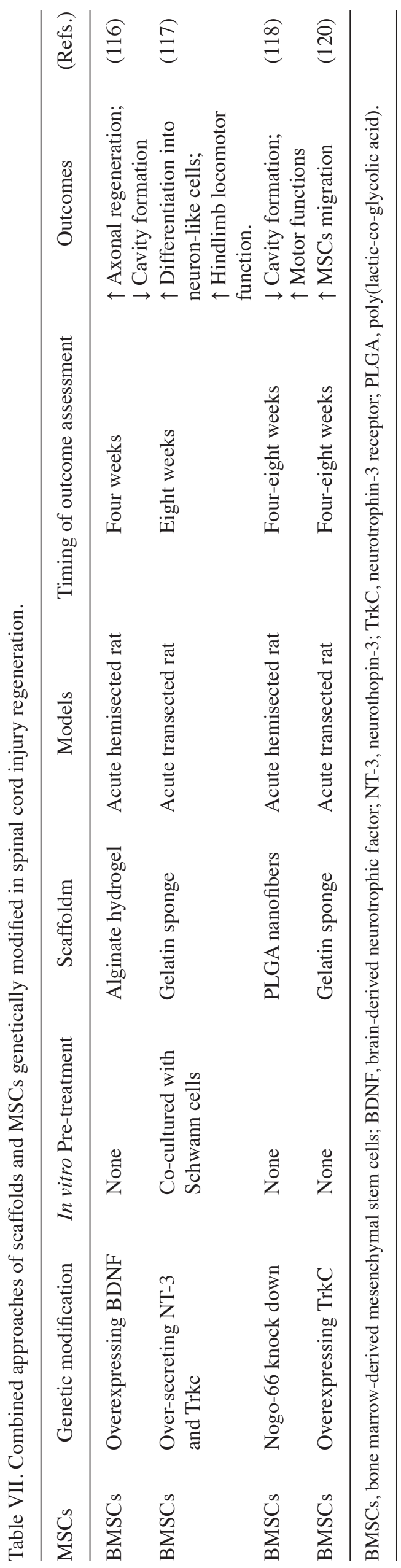


Scaffold was employed to deliver BMSCs, in order to promote nerve regeneration and to bridge the gap present in the site of injury. Moreover, this scaffold showed linear orientated fibers which favor axon guidance. A preliminary resection surgery was performed in order to eliminate the glial scar tissue at the spinal cord, which can interfere with nerve regeneration, followed by transplantation in the resection site of autologous BMSCs seeded on NeuroRegen Scaffold ${ }^{\mathrm{TM}}$. Two months after surgery, it was recorded a partial improvement of autonomic nervous functions in these patients in terms of sexual arousal and sweating in approximately $50 \%$ of patients, as well as an improvement of the somatosensory evoked potential from the lower limbs of in another $50 \%$ of the cohort, six months after surgery. Moreover, since no adverse effects were recorded, this study validated NeuroRegen Scaffold ${ }^{\mathrm{TM}}$ as safe support to be applied in regenerative medicine.

Another clinical trial which has employed the NeuroRegen Scaffold $^{\mathrm{TM}}$ as cell support device for promoting nerve regeneration in SCI, has been just completed in China (122). A total of eight patients (7 male and 1 female with a mean age of 31.5 years) suffering from chronic (2-36 months after injury) complete SCI, according to the ASIA Scale, with C5-T12 lesions, were enrolled in this study. The patients were subjected to surgical resection of glial scar in the spinal cord in order to prevent its inhibitory effect on nerve regeneration. After that, allogenic UCB-MSCs were loaded on NeuroRegen Scaffold $^{\mathrm{TM}}$ and implanted in the resection site. Also in this circumstance, none adverse reaction was registered after one year of follow-up, indicating that these scaffolds possess a good safety profile. On the other hand, positive outcomes have been observed: some patients showed increased recovery of some autonomic neural functions, such as finger activity, trunk stability and defecation sensation (122). Although these two latest studies have been performed by using two different SC sources (BMSCs and UMSCs), either autologous or allogenic, seeded on the same matrix engineered scaffold (NeuroRegen Scaffold ${ }^{\mathrm{TM}}$ ), the clinical outcomes obtained were similar. These findings may indicate that scaffolds play a crucial role in conveying the therapeutic potential of MSCs beyond their derivation, although none biomaterial-based scaffold has been approved to date for treating SCI patients. The clinical studies here reported have been summarized in Table VIII.

\section{Conclusions}

The combined strategy of MSCs and engineered scaffold has showed to be more efficacious compared to MSCs or scaffold transplantation alone. Indeed, MSCs from different sources conjugated with different kinds of scaffolds have shown to promote SCI regeneration and functional recovery, by increasing MSCs adhesion, migration and survival, but in particular by mimicking a more favorable microenvironment that stimulates the endogenous repair. Although the major part of the studies here reported have been focused on BMSCs, other MSCs merit to be further explored, due their marked trend to differentiate toward the neuronal lineage and to potentially replace the damaged neurons. On the other hand, there is no electivity for a specific type of scaffold despite the composites scaffolds have been proposed as the most promising devices, because they minimize the disadvantages

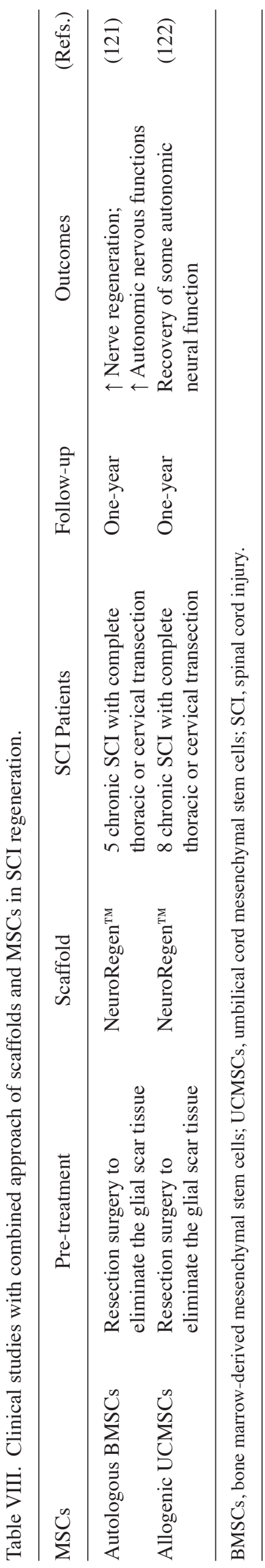


of the single material and synergize the advantages of two materials. Although much progress has been made in the scenario of acute SCI, an exhaustive amount of clinical evidence is still missing, and the treatments for chronic SCI are more challenging. Therefore, multidisciplinary approaches which combine genetically manipulated cells with engineered scaffolds have been proposed as a future perspective for SCI treatment.

\section{Acknowledgements}

This study was supported by current research funds 2016 of Health Ministry to IRCCS Centro Neurolesi 'Bonino-Pulejo'.

\section{References}

1. World Health Organization (WHO): International Perspectives on Spinal Cord Injury. WHO, Geneva, 2016.

2. Thuret S, Moon LDF and Gage FH: Therapeutic interventions after spinal cord injury. Nat Rev Neurosci 7: 628-643, 2006.

3. Schwab ME and Bartholdi D: Degeneration and regeneration of axons in the lesioned spinal cord. Physiol Rev 76: 319-370, 1996.

4. Crowe MJ, Bresnahan JC, Shuman SL, Masters JN and Crowe MS: Apoptosis and delayed degeneration after spinal cord injury in rats and monkeys. Nat Med 3: 73-76, 1997.

5. Choo AM, Liu J, Dvorak M, Tetzlaff W and Oxland TR: Secondary pathology following contusion, dislocation, and distraction spinal cord injuries. Exp Neurol 212: 490-506, 2008.

6. Hausmann ON: Post-traumatic inflammation following spinal cord injury. Spinal Cord 41: 369-378, 2003.

7. Donnelly DJ and Popovich PG: Inflammation and its role in neuroprotection, axonal regeneration and functional recovery after spinal cord injury. Exp Neurol 209: 378-388, 2008.

8. Yiu G and He Z: Glial inhibition of CNS axon regeneration. Nat Rev Neurosci 7: 617-627, 2006.

9. von Euler M, Janson AM, Larsen JO, Seiger A, Forno L, Bunge MB and Sundström E: Spontaneous axonal regeneration in rodent spinal cord after ischemic injury. J Neuropathol Exp Neurol 61: 64-75, 2002.

10. Love S: Degeneration and regeneration in the nervous system Brain 126: 1009-1011, 2003.

11. Silver J and Miller JH: Regeneration beyond the glial scar. Nat Rev Neurosci 5: 146-156, 2004.

12. Gilbert RJ, McKeon RJ, Darr A, Calabro A, Hascall VC and Bellamkonda RV: CS-4,6 is differentially upregulated in glial scar and is a potent inhibitor of neurite extension. Mol Cell Neurosci 29: 545-558, 2005.

13. Fawcett JW: Overcoming inhibition in the damaged spinal cord. J Neurotrauma 23: 371-383, 2006.

14. Consortium for Spinal Cord Medicine: Early acute management in adults with spinal cord injury: A clinical practice guideline for health-care professionals. J Spinal Cord Med 31: 403-479, 2008.

15. Bracken MB: Steroids for acute spinal cord injury. Cochrane Database Syst Rev 1: CD001046, 2012.

16. Morita T, Sasaki M, Kataoka-Sasaki Y, Nakazaki M, Nagahama H, Oka S, Oshigiri T, Takebayashi T, Yamashita T, Kocsis JD and Honmou O: Intravenous infusion of mesenchymal stem cells promotes functional recovery in a model of chronic spinal cord injury. Neuroscience 335: 221-231, 2016.

17. Zhou HL, Zhang XJ, Zhang MY, Yan ZJ, Xu ZM and Xu RX: Transplantation of human amniotic mesenchymal stem cells promotes functional recovery in a rat model of traumatic spinal cord injury. Neurochem Res 41: 2708-2718, 2016.

18. Satti HS, Waheed A, Ahmed P, Ahmed K, Akram Z, Aziz T, Satti TM, Shahbaz N, Khan MA and Malik SA: Autologous mesenchymal stromal cell transplantation for spinal cord injury: A Phase I pilot study. Cytotherapy 18: 518-522, 2016.

19. Ribeiro-Samy S, Silva NA, Correlo VM, Fraga JS, Pinto L, Teixeira-Castro A, Leite-Almeida H, Almeida A, Gimble JM, Sousa N, et al: Development and characterization of a PHB-HV-based 3D scaffold for a tissue engineering and cell-therapy combinatorial approach for spinal cord injury regeneration. Macromol Biosci 13: 1576-1592, 2013.
20. Volpato FZ, Führmann T, Migliaresi C, Hutmacher DW and Dalton PD: Using extracellular matrix for regenerative medicine in the spinal cord. Biomaterials 34: 4945-4955, 2013.

21. Pires LR and Pêgo AP: Bridging the lesion-engineering a permissive substrate for nerve regeneration. Regen Biomater 2: 203-214, 2015.

22. Perale G, Rossi F, Sundstrom E, Bacchiega S, Masi M, Forloni G and Veglianese P: Hydrogels in spinal cord injury repair strategies. ACS Chem Neurosci 2: 336-345, 2011.

23. Macaya D and Spector M: Injectable hydrogel materials for spinal cord regeneration: A review. Biomed Mater 7: 012001, 2012.

24. Lim GJ,Zare S, VanDyke Mand Atala A:Cell Microencapsulation. Springer, New York, NY, pp126-136, 2010.

25. Nicodemus GD and Bryant SJ: Cell encapsulation in biodegradable hydrogels for tissue engineering applications. Tissue Eng Part B Rev 14: 149-165, 2008.

26. Yang F, Murugan R, Wang S and Ramakrishna S: Electrospinning of nano/micro scale poly (l-lactic acid) aligned fibers and their potential in neural tissue engineering. Biomaterials 26: 2603-2610, 2005.

27. Murugan R and Ramakrishna S: Nano-featured scaffolds for tissue engineering: A review of spinning methodologies. Tissue Eng 12: 435-447, 2006.

28. Shelke NB, Lee P, Anderson M, Mistry N, Nagarale RK, Ma XM, Yu X and Kumbar SG: Neural tissue engineering: Nanofiber-hydrogel based composite scaffolds. Polym Adv Technol 27: 42-51, 2016.

29. Cao H, Liu T and Chew SY: The application of nanofibrous scaffolds in neural tissue engineering. Adv Drug Deliv Rev 61: 1055-1064, 2009.

30. Loh QL and Choong C: Three-dimensional scaffolds for tissue engineering applications: Role of porosity and pore size. Tissue Eng Part B Rev 19: 485-502, 2013.

31. Wong FS, Chan BP and Lo ACY: Carriers in cell-based therapies for neurological disorders. Int J Mol Sci 15: 10669-10723, 2014.

32. Gao M, Lu P, Bednark B, Lynam D, Conner JM, Sakamoto J and Tuszynski MH: Templated agarose scaffolds for the support of motor axon regeneration into sites of complete spinal cord transection. Biomaterials 34: 1529-1536, 2013.

33. Rowley JA, Madlambayan G and Mooney DJ: Alginate hydrogels as synthetic extracellular matrix materials. Biomaterials 20 : 45-53, 1999.

34. Prang P, Muller R, Eljaouhari A, Heckmann K, Kunz W, Weber T, Faber C, Vroemen M, Bogdahn U and Weidner N: The promotion of oriented axonal regrowth in the injured spinal cord by alginate-based anisotropic capillary hydrogels. Biomaterials 27 : 3560-3569, 2006.

35. Shi C, Zhu Y, Ran X, Wang M, Su Y and Cheng T: Therapeutic potential of chitosan and its derivatives in regenerative medicine. J Surg Res 133: 185-192, 2006.

36. Jian R, Yixu Y, Sheyu L, Jianhong S, Yaohua Y, Xing S, Qingfeng H, Xiaojian L, Lei Z, Yan Z, et al: Repair of spinal cord injury by chitosan scaffold with glioma ECM and SB216763 implantation in adult rats. J Biomed Mater Res Part A 103: 3259-3272, 2015.

37. Albu MG, Titorencu I and Ghica MV: Collagen-Based Drug Delivery Systems for Tissue Engineering. Biomat Appl Nanomed: 333-358, 2011.

38. Chan EC, Kuo SM, Kong AM, Morrison WA, Dusting GJ, Mitchell GM, Lim SY and Liu GS: Three dimensional collagen scaffold promotes intrinsic vascularisation for tissue engineering applications. PLoS One 11: e0149799, 2016.

39. Johnson PJ, Parker SR and Sakiyama-Elbert SE: Fibrin-based tissue engineering scaffolds enhance neural fiber sprouting and delay the accumulation of reactive astrocytes at the lesion in a subacute model of spinal cord injury. J Biomed Mater Res A 92: 152-163, 2010.

40. Taylor SJ and Sakiyama-Elbert SE: The development of fibrin-based scaffolds for spinal cord regeneration. In: Proceedings of the Second Joint 24th Annual Conference and the Annual Fall Meeting of the Biomedical Engineering Society. Engineering in Medicine and Biology. Vol 1. IEEE, pp479-480, 2002.

41. Subramanian A, Krishnan UM and Sethuraman S: Development of biomaterial scaffold for nerve tissue engineering: Biomaterial mediated neural regeneration. J Biomed Sci 16: 108, 2009.

42. Khan MN, Islam JM and Khan MA: Fabrication and characterization of gelatin-based biocompatible porous composite scaffold for bone tissue engineering. J Biomed Mater Res Part A 100: 3020-3028, 2012. 
43. Zheng Shu X, Liu Y, Palumbo FS, Luo Y and Prestwich GD: In situ crosslinkable hyaluronan hydrogels for tissue engineering. Biomaterials 25: 1339-1348, 2004.

44. Collins MN and Birkinshaw C: Hyaluronic acid based scaffolds for tissue engineering-a review. Carbohydr Polym 92: 1262-1279, 2013.

45. Li ZH, Ji SC, Wang YZ, Shen XC and Liang H: Silk fibroin-based scaffolds for tissue engineering. Front Mater Sci 7: 237-247, 2013.

46. Yan LP, Oliveira JM, Oliveira AL, Caridade SG, Mano JF and Reis RL: Macro/microporous silk fibroin scaffolds with potential for articular cartilage 3 and meniscus tissue engineering applications. Acta Biomater 8: 289-301, 2012.

47. Guo SZ, Ren XJ, Wu B and Jiang T: Preparation of the acellular scaffold of the spinal cord and the study of biocompatibility. Spinal Cord 48: 576-581, 2010

48. Zhang XY, Xue H, Liu JM and Chen D: Chemically extracted acellular muscle: A new potential scaffold for spinal cord injury repair. J Biomed Mater Res Part A 100: 578-587, 2012.

49. Lopes MS, Jardini AL and Filho RM: Poly (lactic acid) production for tissue engineering applications. Procedia Eng 42: 1402-1413, 2012.

50. Wang GJ, Ho KH and Hsueh CC: Biodegradable polylactic acid (PLA) microstructures for scaffold applications. Biodegrad Polylactic Acid: 260-263, 2007.

51. Boland ED, Wnek GE, Simpson DG, Pawlowski KJ and Bowlin GL: Tailoring tissue engineering scaffolds using electrostatic processing techniques: A study of poly (Glycolic Acid) electrospinning. Cornell Univ Lib 38: 1231-1243, 2001.

52. Shum AW and Mak AF: Morphological and biomechanical characterization of poly (glycolic acid) scaffolds after in vitro degradation. Polym Degrad Stab 81: 141-149, 2003.

53. Kranz H, Ubrich N, Maincent $P$ and Bodmeier $R$ : Physicomechanical properties of biodegradable poly (D,L-lactide) and poly (D,L-lactide-co-glycolide) films in the dry and wet states. J Pharm Sci 89: 1558-1566, 2000.

54. Makadia HK and Siegel SJ: Poly lactic-co-glycolic acid (PLGA) as biodegradable controlled drug delivery carrier. Polymers (Basel) 3: 1377-1397, 2011

55. Ginestra P, Ceretti E and Fiorentino A: Electrospinning of poly-caprolactone for scaffold manufacturing: Experimental investigation on the process parameters influence. Procedia CIRP 49: 8-13, 2016.

56. Donoghue PS, Lamond R, Boomkamp SD, Sun T, Gadegaard N, Riehle MO and Barnett SC: The development of a $\varepsilon$-polycaprolactone scaffold for central nervous system repair. Tissue Eng Part A 19: 497-507, 2013.

57. Ulery BD, Nair LS and Laurencin CT: Biomedical applications of biodegradable polymers. J Polym Sci B Polym Phys 49: 832-864, 2011.

58. Tan W, Krishnaraj R and Desai TA: Evaluation of nanostructured composite collagen-chitosan matrices for tissue engineering. Tissue Eng 7: 203-210, 2001.

59. Zhang M, Li XH, Gong YD, Zhao NM and Zhang XF: Properties and biocompatibility of chitosan films modified by blending with PEG. Biomaterials 23: 2641-2648, 2002.

60. Chung TW, Yang J, Akaike T, Cho KY, Nah JW, Kim SIl and Cho CS: Preparation of alginate/galactosylated chitosan scaffold for hepatocyte attachment. Biomaterials 23: 2827-2834, 2002.

61. O'Brien FJ: Biomaterials \& scaffolds for tissue engineering. Mater Today 14: 88-95, 2011

62. Zhu J and Marchant RE: Design properties of hydrogel tissue-engineering scaffolds. Expert Rev Med Devices 8: 607-626, 2011

63. Dhandayuthapani B, Yoshida Y, Maekawa T and Kumar DS Polymeric scaffolds in tissue engineering application: A review. Int J Polym Sci 2011: 1-19, 2011.

64. Nigam R and Mahanta B: An overview of various biomimetic scaffolds: Challenges and applications in tissue engineering. J Tissue Sci Eng 5: 1-5, 2014.

65. Zhang SX, Huang F, Gates M and Holmberg EG: Role of endogenous Schwann cells in tissue repair after spinal cord injury. Neural Regen Res 8: 177-185, 2013.

66. Kim BG, Hwang DH, Lee SI, Kim EJ and Kim SU: Stem cell-based cell therapy for spinal cord injury. Cell Transplant 16: 355-364, 2007.

67. Law S and Chaudhuri S: Mesenchymal stem cell and regenerative medicine: Regeneration versus immunomodulatory challenges. Am J Stem Cells 2: 22-38, 2013
68. Dominici M, Le Blanc K, Mueller I, Slaper-Cortenbach I, Marini F, Krause D, Deans R, Keating A, Prockop DJ and Horwitz E: Minimal criteria for defining multipotent mesenchymal stromal cells. Cytotherapy 8: 315-317, 2006.

69. Bara JJ, Richards RG, Alini M and Stoddart MJ: Concise Review: Bone marrow-derived mesenchymal stem cells change phenotype following in vitro culture: Implications for basic research and the clinic. Stem Cells 32: 1713-1723, 2014.

70. Nagamura-Inoue $\mathrm{T}$ and $\mathrm{He} \mathrm{H}$ : Umbilical cord-derived mesenchymal stem cells: Their advantages and potential clinical utility. World J Stem Cells 6: 195-202, 2014.

71. Oliveira MS and Barreto-Filho JB: Placental-derived stem cells: Culture, differentiation and challenges. World J Stem Cells 7: 769-775, 2015

72. Mahmoudifar N and Doran PM: Mesenchymal Stem Cells Derived from Human Adipose Tissue. In: Methods in molecular biology. Doran PM (ed). Vol 1340. Springer New York, NY, pp53-64, 2015.

73. Wouters G, Grossi S, Mesoraca A, Bizzoco D, Mobili L, Cignini $\mathrm{P}$ and Giorlandino C: Isolation of amniotic fluid-derived mesenchymal stem cells. J Prenat Med 1: 39-40, 2007.

74. Huang GT, Gronthos S and Shi S: Mesenchymal stem cells derived from dental tissues vs, those from other sources: Their biology and role in regenerative medicine. J Dent Res 88: 792-806, 2009

75. Parr AM, Tator $\mathrm{CH}$ and Keating A: Bone marrow-derived mesenchymal stromal cells for the repair of central nervous system injury. Bone Marrow Transplant 40: 609-619, 2007.

76. Wislet-Gendebien S, Wautier F, Leprince P and Rogister B: Astrocytic and neuronal fate of mesenchymal stem cells expressing nestin. Brain Res Bull 68: 95-102, 2005.

77. Lavoie JR and Rosu-Myles M: Uncovering the secretes of mesenchymal stem cells. Biochimie 95: 2212-2221, 2013.

78. Chopp M, Zhang XH, Li Y, Wang L, Chen J, Lu D, Lu M and Rosenblum M: Spinal cord injury in rat: Treatment with bone marrow stromal cell transplantation. Neuroreport 11: 3001-3005, 2000.

79. Gu W, Zhang F, Xue Q, Ma Z, Lu P and Yu B: Transplantation of bone marrow mesenchymal stem cells reduces lesion volume and induces axonal regrowth of injured spinal cord. Neuropathology 30: 205-217, 2009.

80. Forostyak S, Jendelova P and Sykova E: The role of mesenchymal stromal cells in spinal cord injury, regenerative medicine and possible clinical applications. Biochimie 95: 2257-2270, 2013.

81. Itosaka H, Kuroda S, Shichinohe H, Yasuda H, Yano S, Kamei S, Kawamura R, Hida K and Iwasaki Y: Fibrin matrix provides a suitable scaffold for bone marrow stromal cells transplanted into injured spinal cord: A novel material for CNS tissue engineering. Neuropathology 29: 248-257, 2009.

82. Basso DM, Beattie MS and Bresnahan JC: A sensitive and reliable locomotor rating scale for open field testing in rats. J Neurotrauma 12: 1-21, 1995.

83. Kim YC, Kim YH, Kim JW and Ha KY: Transplantation of mesenchymal stem cells for acute spinal cord injury in rats: Comparative study between intralesional injection and scaffold based transplantation. J Korean Med Sci 31: 1373-1382, 2016

84. Han S, Wang B, Li X, Xiao Z, Han J, Zhao Y, Fang Y, Yin Y, Chen B and Dai J: Bone marrow-derived mesenchymal stem cells in three-dimensional culture promote neuronal regeneration by neurotrophic protection and immunomodulation. J Biomed Mater Res Part A 104: 1759-1769, 2016.

85. Zeng X,Zeng Y,Ma Y,Lu LY,Du BL, Zhang W,Li Y and Chan WY: Bone marrow mesenchymal stem cells in a three-dimensional gelatin sponge scaffold attenuate inflammation, promote angiogenesis and reduce cavity formation in experimental spinal cord injury. Cell Transplant 20: 1881-1899, 2011.

86. Wang YH, Chen J, Zhou J, Nong F, Lv JH and Liu J: Reduced inflammatory cell recruitment and tissue damage in spinal cord injury by acellular spinal cord scaffold seeded with mesenchymal stem cells. Exp Ther Med 13: 203-207, 2017.

87. Chen J, Zhang Z, Liu J, Zhou R, Zheng X, Chen T, Wang L, Huang M, Yang C, Li Z, et al: Acellular spinal cord scaffold seeded with bone marrow stromal cells protects tissue and promotes functional recovery in spinal cord-injured rats. J Neurosci Res 92: 307-317, 2014

88. Li G, Che MT, Zhang K, Qin LN, Zhang YT, Chen RQ, Rong LM, Liu S, Ding Y, Shen HY, et al: Graft of the NT-3 persistent delivery gelatin sponge scaffold promotes axon regeneration, attenuates inflammation, and induces cell migration in rat and canine with spinal cord injury. Biomaterials 83: 233-248, 2016. 
89. Grill R, Murai K, Blesch A, Gage FH and Tuszynski MH: Cellular delivery of neurotrophin-3 promotes corticospinal axonal growth and partial functional recovery after spinal cord injury. J Neurosci 17: 5560-5572, 1997.

90. Raynald, Li Y, Yu H, Huang H, Guo M, Hua R, Jiang F, Zhang K, Li H, Wang F, et al: The hetero-transplantation of human bone marrow stromal cells carried by hydrogel unexpectedly demonstrates a significant role in the functional recovery in the injured spinal cord of rats. Brain Res 1634: 21-33, 2016.

91. Zaminy A, Shokrgozar MA, Sadeghi Y, Noroozian M, Heidari MH and Piryaei A: Mesenchymal stem cells as an alternative for Schwann cells in rat spinal cord injury. Iran Biomed J 17: 113-122, 2013.

92.Friedenstein AJ, Chailakhjan RK and Lalykina KS: The development of fibroblast colonies in monolayer cultures of guinea-pig bone marrow and spleen cells. Cell Tissue Kinet 3: 393-403, 1970.

93.Ebrahimi-Barough S, Norouzi Javidan A, Saberi H, Joghataei MT, Rahbarghazi R, Mirzaei E, Faghihi F, Shirian S, $\mathrm{Ai} \mathrm{A}$ and Ai J: Evaluation of motor neuron-like cell differentiation of hEnSCs on biodegradable PLGA nanofiber scaffolds. Mol Neurobiol 52: 1704-1713, 2015.

94. Shirian S, Ebrahimi-Barough S, Saberi H, Norouzi-Javidan A, Mousavi SM, Derakhshan MA, Arjmand B and Ai J Comparison of capability of human bone marrow mesenchymal stem cells and endometrial stem cells to differentiate into motor neurons on electrospun poly ( $\varepsilon$-caprolactone) scaffold. Mol Neurobiol 53: 5278-5287, 2016.

95.Ebrahimi-Barough S, Hoveizi E, Yazdankhah M, Ai J Khakbiz M, Faghihi F, Tajerian R and Bayat N: Inhibitor of PI3K/Akt signaling pathway small molecule promotes motor neuron differentiation of human endometrial stem cells cultured on electrospun biocomposite polycaprolactone/collagen scaffolds. Mol Neurobiol 54: 2547-2554, 2017

96. Terraf P, Kouhsari SM, Ai J and Babaloo H: Tissue-engineered regeneration of hemisected spinal cord using human endometrial stem cells, poly $\varepsilon$-caprolactone scaffolds, and crocin as a neuroprotective agent. Mol Neurobiol: Sep 13, 2016 (Epub ahead of print).

97. Zaminy A, Shokrgozar MA, Sadeghi Y, Norouzian M, Heidari MH and Piryaei A: Transplantation of schwann cells differentiated from adipose stem cells improves functional recovery in rat spinal cord injury. Arch Iran Med 16: 533-541, 2013

98. Gao S, Zhao P, Lin C, Sun Y, Wang Y, Zhou Z, Yang D, Wang X, $\mathrm{Xu} \mathrm{H}$, Zhou F, et al: Differentiation of human adipose-derived stem cells into neuron-like cells which are compatible with photocurable three-dimensional scaffolds. Tissue Eng Part A 20 1271-1284, 2014

99. Ji W, Zhang Y, Hu S and Zhang Y: Biocompatibility study of a silk fibroin-chitosan scaffold with adipose tissue-derived stem cells in vitro. Exp Ther Med 6: 513-518, 2013.

100. Caron I, Rossi F, Papa S, Aloe R, Sculco M, Mauri E, Sacchetti A, Erba E, Panini N, Parazzi V, et al: A new three dimensional biomimetic hydrogel to deliver factors secreted by human mesenchymal stem cells in spinal cord injury. Biomaterials 75 : 135-147, 2016.

101. Bellis SL: Advantages of RGD peptides for directing cell association with biomaterials. Biomaterials 32: 4205-4210, 2011

102. Anderson SB, Lin CC, Kuntzler DV and Anseth KS: The performance of human mesenchymal stem cells encapsulated in cell-degradable polymer-peptide hydrogels. Biomaterials 32 3564-3574, 2011.

103. Liu J, Chen J, Liu B, Yang C, Xie D, Zheng X, Xu S, Chen T, Wang L, Zhang Z, et al: Acellular spinal cord scaffold seeded with mesenchymal stem cells promotes long-distance axon regeneration and functional recovery in spinal cord injured rats J Neurol Sci 325: 127-136, 2013

104. Jiao G, Lou G, Mo Y, Pan Y, Zhang Z, Guo R and Li Z: A combination of GDNF and hUCMSC transplantation loaded on SF/AGs composite scaffolds for spinal cord injury repair. Mater Sci Eng C Mater Biol Appl 74: 230-237, 2017.

105. Li X, Tan J, Xiao Z, Zhao Y, Han S, Liu D, Yin W, Li J, Li J, Wanggou S, et al: Transplantation of hUC-MSCs seeded collagen scaffolds reduces scar formation and promotes functional recovery in canines with chronic spinal cord injury. Sci Rep 7: 43559, 2017.
106. Lin H, Chen B, Wang B, Zhao Y, Sun W and Dai J: Novel nerve guidance material prepared from bovine aponeurosis. J Biomed Mater Res A 79: 591-598, 2006.

107. Wang TG, Xu J, Zhu AH, Lu H, Miao ZN, Zhao P, Hui GZ and Wu WJ: Human amniotic epithelial cells combined with silk fibroin scaffold in the repair of spinal cord injury. Neural Regen Res 11: 1670-1677, 2016

108. Xue H, Zhang XY, Liu JM, Song Y, Li YF and Chen D: Development of a chemically extracted acellular muscle scaffold seeded with amniotic epithelial cells to promote spinal cord repair. J Biomed Mater Res Part A 101: 145-156, 2013.

109. Sakai K, Yamamoto A, Matsubara K, Nakamura S, Naruse M, Yamagata M, Sakamoto K, Tauchi R, Wakao N, Imagama S, et al: Human dental pulp-derived stem cells promote locomotor recovery after complete transection of the rat spinal cord by multiple neuro-regenerative mechanisms. J Clin Invest 122: 80-90, 2012

110. Bray AF, Cevallos RR, Gazarian K and Lamas AM: Human dental pulp stem cells respond to cues from the rat retina and differentiate to express the retinal neuronal marker rhodopsin. Neuroscience 280: 142-155, 2014.

111. Nicola FC, Rodrigues LP, Crestani T, Quintiliano K, Sanches EF, Willborn S, Aristimunha D, Boisserand L, Pranke P and Netto CA: Human dental pulp stem cells transplantation combined with treadmill training in rats after traumatic spinal cord injury. Braz J Med Biol Res 49: e5319, 2016.

112. Yamamoto A, Sakai K, Matsubara K, Kano F and Ueda M: Multifaceted neuro-regenerative activities of human dental pulp stem cells for functional recovery after spinal cord injury. Neurosci Res 78: 16-20, 2014.

113. Mayo V, Sawatari Y, Huang CYC and Garcia-Godoy F: Neural crest-derived dental stem cells-where we are and where we are going. J Dent 42: 1043-1051, 2014

114. Zhang J, Lu X, Feng G, Gu Z, Sun Y, Bao G, Xu G, Lu Y, Chen J, $\mathrm{Xu}$ L, et al: Chitosan scaffolds induce human dental pulp stem cells to neural differentiation: Potential roles for spinal cord injury therapy. Cell Tissue Res 366: 129-142, 2016.

115. Cui X, Chen L, Ren Y, Ji Y, Liu W, Liu J, Yan Q, Cheng L and Sun YE: Genetic modification of mesenchymal stem cells in spinal cord injury repair strategies. Biosci Trends 7: 202-208, 2013.

116. Günther MI, Weidner N, Müller R and Blesch A: Cell-seeded alginate hydrogel scaffolds promote directed linear axonal regeneration in the injured rat spinal cord. Acta Biomater 27: $140-150,2015$

117. Zeng X, Qiu XC, Ma YH, Duan JJ, Chen YF, Gu HY, Wang JM, Ling EA, Wu JL, Wu W and Zeng YS: Integration of donor mesenchymal stem cell-derived neuron-like cells into host neural network after rat spinal cord transection. Biomaterials 53: 184-201, 2015

118. Wang D, Fan Y and Zhang J: Transplantation of Nogo-66 receptor gene-silenced cells in a poly (D,L-lactic-co-glycolic acid) scaffold for the treatment of spinal cord injury. Neural Regen Res 8: 677-685, 2013.

119. GrandPré T, Li S and Strittmatter SM: Nogo-66 receptor antagonist peptide promotes axonal regeneration. Nature 417: 547-551, 2002.

120. Chen YF, Zeng X, Zhang K, Lai BQ, Ling EA and Zeng YS: Neurotrophin-3 stimulates migration of mesenchymal stem cells overexpressing TrkC. Curr Med Chem 20: 3022-3033, 2013.

121. Xiao Z, Tang F, Tang J, Yang H, Zhao Y, Chen B, Han S, Wang N, Li X, Cheng S, et al: One-year clinical study of NeuroRegen scaffold implantation following scar resection in complete chronic spinal cord injury patients. Sci China Life Sci 59: 647-655, 2016.

122. Zhao Y, Tang F, Han G, Han G, Wang N, Yin N, Chen B, Jiang X, Yun C, Han W, et al: Clinical study of NeuroRegen scaffold combined with human mesenchymal stem cells for the repair of chronic complete spinal cord injury. Cell Transplant 26: 891-900, 2017. 